\title{
Virtual reality training simulator for tooth preparation techniques
}

\author{
HeeSuk Jung ${ }^{1}$, HyoJoon $\mathrm{Kim}^{2}$, SeongYong Moon ${ }^{2 *}$ \\ ${ }^{1}$ First Dental Clinic, Incheon, Korea \\ ${ }^{2}$ Department of Oral and Maxillofacial Surgery, School of Dentistry, Chosun University, Gwangju, Korea
}

Standard oral and maxillofacial three-dimensional model was developed with patients' medical data while virtual reality (VR) simulator was developed in conjunction with head mount display (HMD) and Haptic device. The objective of this study was to evaluate the preclinical use of a VR training simulator in tooth preparation practice. Eighty-nine dental students were trained how to operate the simulator. The participants were then given sufficient time on the simulator to practice dental preparation. The students experience and opinion was then taken in through filling of questionnaires. On average content received 1.8 points, anatomy had 2.5 points, 2.6 points for the applicability, and 2.0 for the usability. As for the detailed items scores, queries about the possible development of the simulator and the interest of the learning process through the simulator were the highest at 3.1 and 3.0 points, respectively. Question about the benefit of the HMD and the haptic device during the practice had 1.5 and 1.6 points, respectively. The average total score was 2.2 points. VR tooth preparation simulator in the field of clinical dental education has powerful potential in regard to realistic models, environments, vision, posture, and economical efficiency.

Key Words: Dental caries, Dental education, Tooth preparation, Virtual reality

(c) This is an open-access article distributed under the terms of the Creative Commons Attribution Non-Commercial License (http://creativecommons.org/licenses/by-nc/4.0) which permits unrestricted noncommercial use, distribution, and reproduction in any medium, provided the original work is properly cited.

\section{INTRODUCTION}

Virtual reality (VR) is a fully three-dimensional (3D) computer-generated 'world' in which a person can move about and interact as if he actually were in this imaginary place [1]. In 1938, Artaud [2] of France first mentioned in his play. And in 1992, Lanier [3] coined the term VR to bring all of the virtual projects under a single rubric [4]. Since the 1990s, it has attracted attention with the development of computers. Recently, commercialized head mount displays (HMDs) have become commonplace, and they have become common in reality. VR is applied in various fields, such as manufacturing, education, medical care, and health care, with entertainment fields, such as games and media. In particular, VR - based learning can enhance learning intention and academic achievement through learner-led experiential learning [5]. Especially, it is useful to apply in educational field which are hard to observe or difficult to visualize, or dangerous or costly experiment [6,7].

Dental education, especially education in the preclinical field, includes observation classes of various dental

Received November 21, 2018; Revised November 22, 2018; Accepted November 23, 2018

Corresponding author: SeongYong Moon, Department of Oral and Maxillofacial Surgery, School of Dentistry, Chosun University, 303 Pilmundaero, Dong-gu, Gwangju 61452, Korea.

Tel: +82-62-220-3810, Fax: +82-62-224-9172, E-mail: msygood@chosun.ac.kr

Copyright $\odot$ 2018, Oral Biology Research Institute 
procedures and practical training for each procedure. Among these classes, appropriate tooth preparation procedures in rehabilitation is considered to be one of the most important clinical practice [8]. However, in the case of small teeth, the process of an ideal tooth preparation with a tolerance of about $1 \mathrm{~mm}$ is difficult to observe in actual clinical observation environment, and it is difficult to explain and evaluate it in practical training classes [9]. Currently, most dental colleges use tooth models (dentiform) to practice teeth preparation techniques. And assessment of tooth preparation is done with the naked eye. Several studies have been conducted to improve this process [10-12]. Aragon and Zibrowski [13] reported on the improvement of learning effect through "procedural video' in preclinical education related to tooth preparation for ceramic crown. Robinson and Lee [14] reported the effectiveness of training using real-time magnified video using microscopy in teaching tooth preparation.

The purpose of this study was to investigate the effectiveness of VR and its applicability to the field of dentistry after applying this learning environment to real dental students.

\section{MATERIALS AND METHODS}

\section{Development of VR tooth preparation simulator}

The medical images such as computed tomography (CT), oral scan, and magnetic resonance imaging of

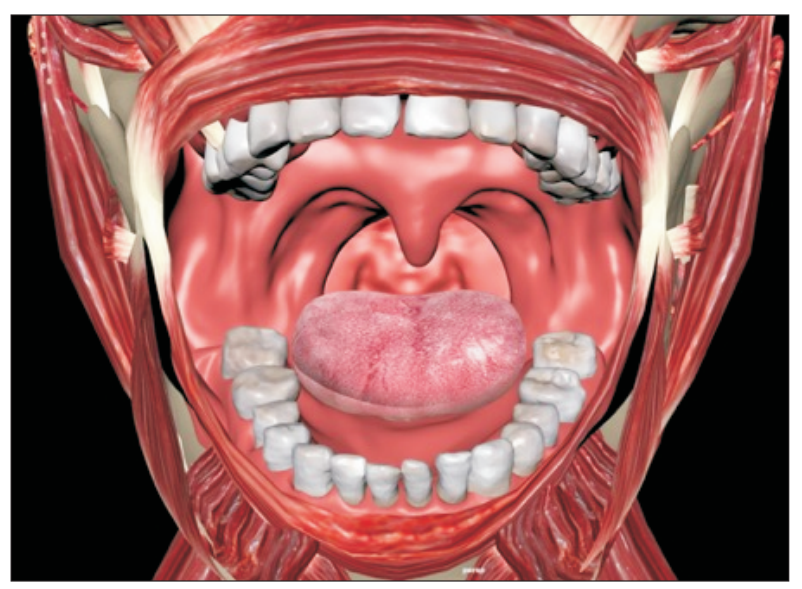

Fig. 1. Oral and maxillofacial three-dimensional model. patients were made into 3D imaged and standard oral and maxillofacial 3D model was developed. In addition, standard caries models were developed using the oral scan data and the CT data for teeth of patients treated with actual dental caries (Fig. 1, 2). The VR tooth preparation simulator was developed with Unity 3D conjunction with HTC Vive Pro VR headset (HTC Co., Bellevue, WA, USA) and the Haptic controller (Geomagic touch; 3D Systems, Inc., Rock Hill, SC, USA). For realizing the actual clinical environment, standard oral and maxillofacial 3D model and the standard caries model implemented into the VR simulator (Fig. 3). The working length of the simulator and the position of the haptic controller are the same as those

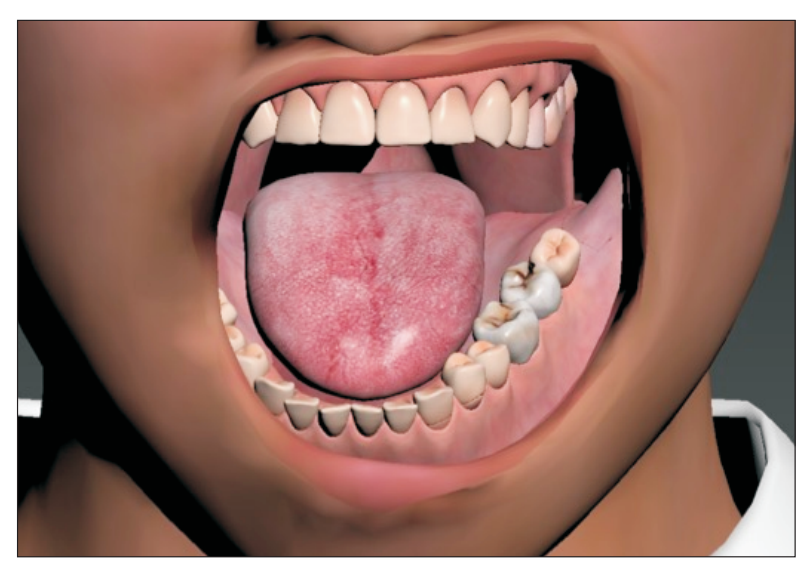

Fig. 2. Developed oral cavity and dental caries three-dimensional model.

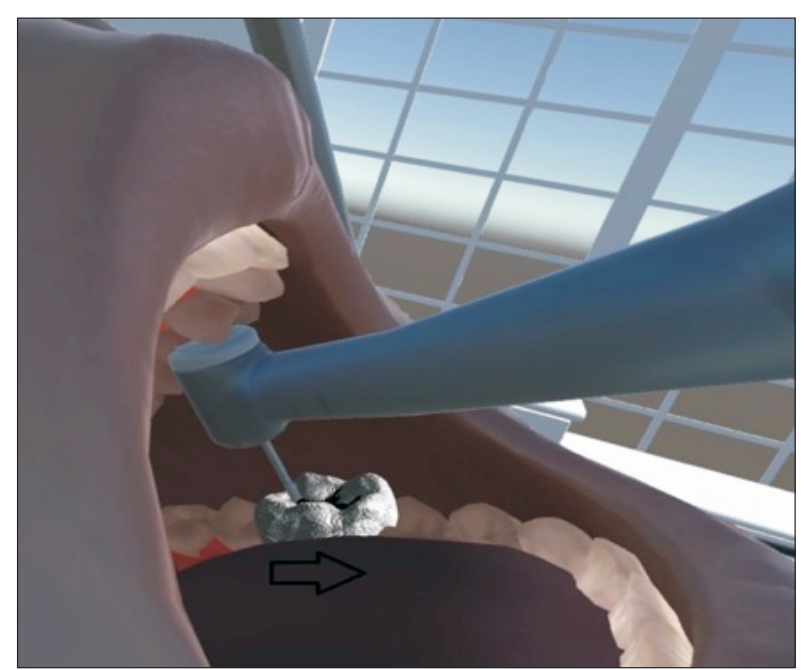

Fig. 3. Virtual reality tooth preparation simulator: Practitioner's view (arrow). 
of the dental procedure. A dedicated table was constructed so that the patient could sit in the dental chair and configure the same environment [15] as the leg balanced seating position (Fig. 4). We have defined the ideal tooth cavity preparation in the implemented simulator. After that, the evaluation system was implemented to compare the cavity preparation of the practitioner with the shape of the ideal tooth cavity preparation and to show the difference

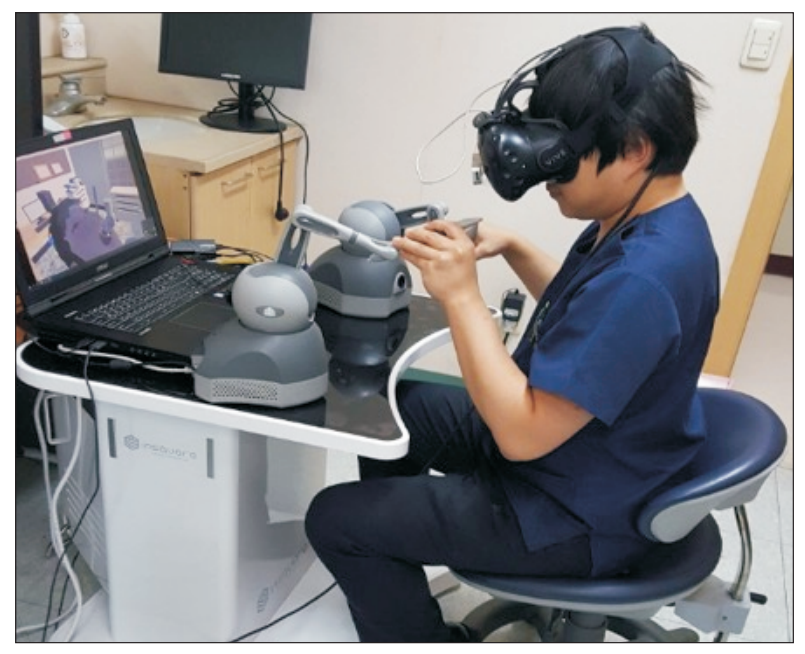

Fig. 4. Balanced seating position of the simulator.
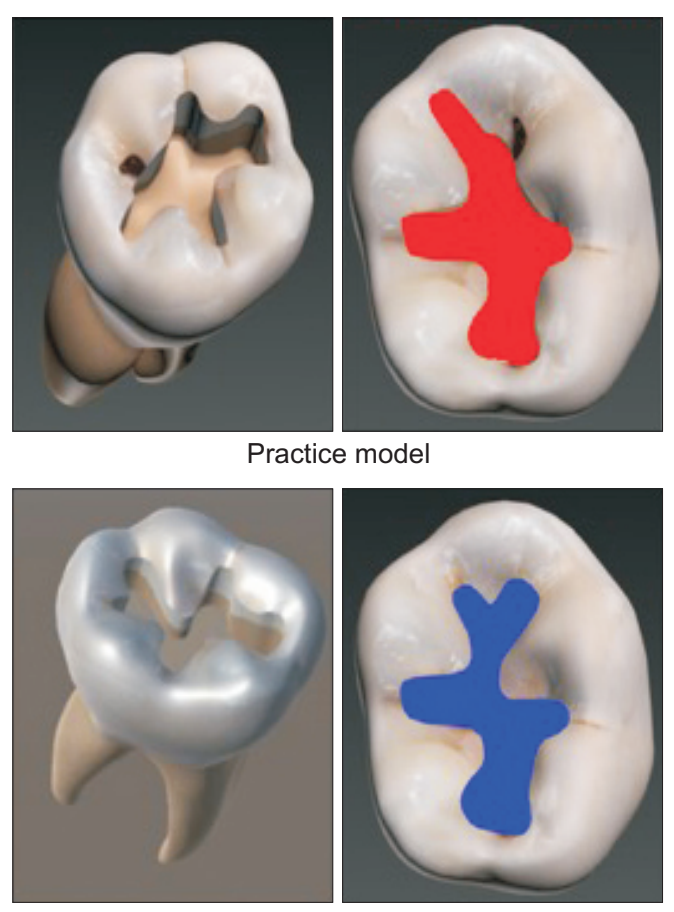

Ideal model

between the two models, so that the practitioner can identify the results of their practice (Fig. 5).

\section{Evaluation of the developed VR tooth preparation simulator}

Eighty-nine dental college students who are receiving preclinical education and training about how to operate the simulator and how to practice it, were attended and each of them was allowed to practice through the tooth preparation simulator for a sufficient time. Questionnaires are divided into four sections: content, anatomy, applicability, and usability. In the content item, the completeness of the content of the training simulation was confirmed. In the section of the anatomy, it is possible to evaluate the accuracy of the anatomical structure of the oral cavity, the external shape and the internal shape of the tooth during the practice. In the applicability category, we evaluated the applicability of the simulator to the practical education, such as the interest and the usefulness of the practical training. In the usability item, we assessed the inconvenience of the practice using the VR simulator and the realism similarity of the practice using each device. It

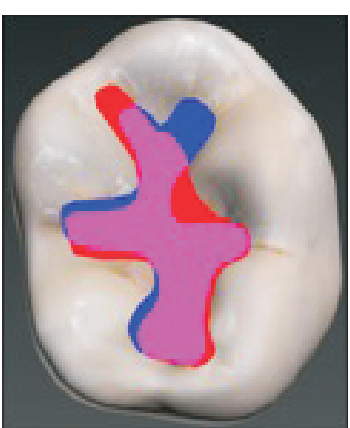

Evaluation
Fig. 5. Virtual reality tooth preparation simulator: Evaluation system. 
Table 1. Survey items and mean scores for the VR preparation simulator

\begin{tabular}{|c|c|c|}
\hline Section & Questionaire & Mean score \\
\hline \multirow[t]{6}{*}{ Content } & Is the accuracy of the tooth preparation simulator acceptable when compared to the actual clinical? & 1.70 \\
\hline & Is it possible to check the whole process of the tooth preparation in the simulator? & 1.85 \\
\hline & Is the order of the tooth preparation process implemented correctly? & 1.93 \\
\hline & Is the practice of using HMDs more beneficial when compared to traditional practice (using dentiforms)? & 1.53 \\
\hline & Is the practice of using haptic devices more beneficial when compared to existing practice (using dentiforms)? & 1.56 \\
\hline & Is learning of tooth preparation process using simulator more effective than existing book or video education? & 2.07 \\
\hline \multirow[t]{4}{*}{ Anatomy } & The anatomical structure in the oral cavity is accurately implemented. & 2.48 \\
\hline & The shape of the teeth are similar to the actual patient. & 2.60 \\
\hline & The structure of the tooth corresponds to the real anatomical structure. & 2.48 \\
\hline & A three-dimensional anatomic model is likely to be helpful in understanding anatomy. & 2.43 \\
\hline \multirow[t]{6}{*}{ Applicability } & The process of practicing with the simulator is interesting. & 2.97 \\
\hline & It is beneficial for learning tooth preparation process. & 2.44 \\
\hline & Using this VR simulator is helpful to reduce the gap between clinical in actual patients and model practice. & 2.16 \\
\hline & I think that the existing dental education curriculum should include the practice using the VR simulator. & 2.21 \\
\hline & I want to learn other dental practice by using VR simulator. & 2.44 \\
\hline & There is a possibility of future development of the tooth preparation simulator. & 3.13 \\
\hline \multirow[t]{7}{*}{ Usability } & In practice, HMD felt comfortable. & 1.82 \\
\hline & The quality of the video at the time of practice is good. & 1.86 \\
\hline & The sound quality at the time of practice is good. & 1.86 \\
\hline & The operation using the haptic device is similar to the operation of the actual handpiece. & 1.79 \\
\hline & The viewpoint using HMD is similar to reality. & 1.97 \\
\hline & I did not feel aching, dizziness, or headache when I practiced. & 2.59 \\
\hline & Practice using VR simulator seemed comfortable. & 2.24 \\
\hline
\end{tabular}

VR, virtual reality; HMD, head mount display.

consists of a total of 23 items, each item is as follows (Table 1). For each item, the evaluation was made from 0 to 4 points. In addition to the evaluation through the evaluation items, additional testimonials were written so that the testimonials, deficiencies, and remedies of VR simulator could be written freely.

\section{RESULTS}

The average score of each item and the average score of each sub item are shown in Fig. 6 and Table 1. Content received 1.8 points on the average, 2.5 points on the anatomy, 2.6 points on the applicability, and 2.0 on the usability. As for the scores for detailed items, items that asked about the possibility of development of the simulator and the interest of the learning process through the simulator were the highest score of 3.1 and 3.0, respectively. In the question about the benefit of the HMD and the haptic device during the practice were 1.5 and 1.6 points, respectively. The average total score was 2.2 points. In addition to the questionnaire items, most of the demonstration impressions were that the procedure of preparation the teeth in the desired form was difficult because the size of the tooth to be practiced 


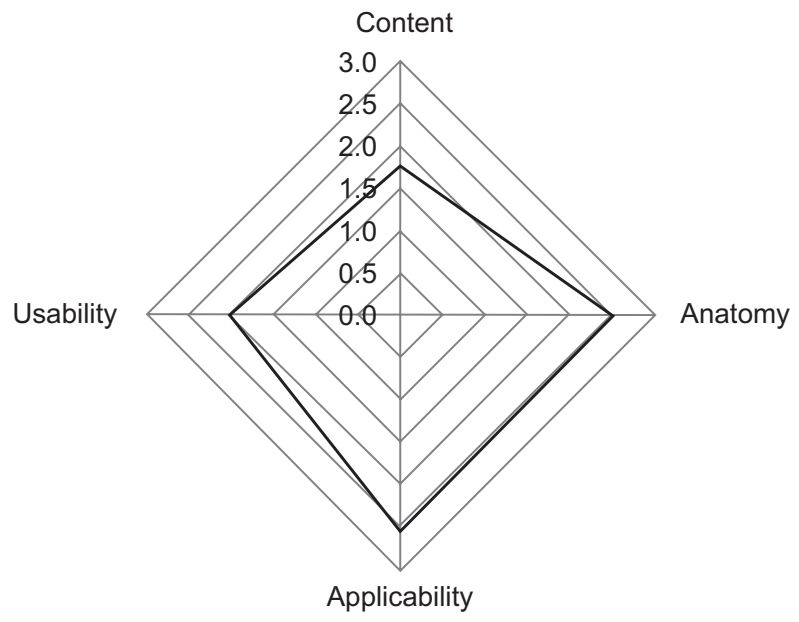

Fig. 6. Overall mean scores for the virtual reality preparation simulator.

was too small compared to the resolution of the VR image viewed through the HMD. In addition, haptic devices have limitations on the operation radius, and it was difficult to obtain a practical posture according to the desired position. The training course and content were interesting, but further research and development were needed to apply it to practical clinical practice.

\section{DISCUSSION}

Arnetzl and Dornhofer [16] introduced the process of assessment of the performance results after teeth preparation. With the 3D scanner can evaluate the actual depth and angle by a computer system, if evaluation method was more accurate and the practitioner's technique helped to improve it. In this study, it is more innovative than Arnetzl and Dornhofer's [16] method because it can be directly evaluated without 3D scanner because this simulator practice with 3D realistic model and had the evaluating system itself. Marras et al. [17] have developed a VR simulator for the practice of cavity preparation in endodontics using a haptic device, which is useful for learners to learn and acquire practical training procedures and methods. However, there is a difference between the actual clinical experience and the system that only monitors the screen of the monitor, which can be overcome through the HMD used in this study. Compared to the VR environment using HMD, the problem of resolution caused by small tooth size is one of the most important problems to be solved. Pulijala et al. [18] reported on VR simulation for orthgnathic surgery training and reported that it is useful for educator's experience improvement and training of various surgical tools. However, compared to orthognathic surgery, tooth preparation is very small and elaborate, making it difficult to practice and evaluate the current resolution. Future research will need to improve the resolution or resolution of the enlargement of the tooth part in part. One of the major side effects of VR using HMD is VR sickness. It is known that this is caused by the difference between the viewpoint movement in the VR and the movement in the actual body, and it causes the restriction of the long time use of various VR contents [19]. However, in the results of the VR preparation simulator of this study, the score of the item related to dizziness was 2.59 points, which did not appeal most inconveniences. This is because only the static method of moving the viewpoint by moving only the position and direction of the head is used, and the movement of the viewpoint on the HMD and the body movements of the actual practitioner are mostly in agreement. Therefore, adverse effects such as VR motion sickness will not act as a stumbling block in practice using VR in the tooth preparation process.

\section{CONCLUSION}

In conclusion, after developing the dental preparation simulator which can be used in preclinical dental education, the applicability was evaluated. Conclusively, newly developed simulator enables connection knowledge and practical teeth preparation performance for the students. There is a limitation of the resolution of the HMD device which is improved and supplemented later, it will be a good complementary material for practice using VR in preclinical education. VR tooth preparation simulator in the field of clinical dental education has powerful potential in terms of realistic models, environments, vision, posture, and economical efficiency.

\section{ACKNOWLEDGEMENTS}

This research was financially supported by the 
Ministry of SMEs and Startups (MSS), Korea, under the 'Regional Specialized Industry Development Program (R\&D R0006026)' supervised by the Korea Institute for Advancement of Technology (KIAT).

\section{CONFLICTS OF INTEREST}

The authors declare that they have no competing interests.

\section{ORCID}

\author{
HeeSuk Jung \\ https://orcid.org/0000-0002-6352-0818 \\ HyoJoon Kim \\ https://orcid.org/0000-0001-6123-4810 \\ SeongYong Moon \\ https://orcid.org/0000-0002-7513-4404
}

\section{REFERENCES}

1. Satava RM. Virtual reality surgical simulator. Surg Endosc 1993;7:203-205. doi: 10.1007/BF00594110.

2. Artaud A, Corti V. The theatre and its double. Richmond: Alma Books; 2018.

3. Lanier J. Virtual reality: the promise of the future. Interact Learn Int 1992;8:275-279.

4. Steuer J. Defining virtual reality: dimensions determining telepresence. J Commun 1992;42:73-93. doi: 10.1111/j.14 60-2466.1992.tb00812.x.

5. Milgram P, Takemura H, Utsumi A, Kishino F. Augmented reality: a class of displays on the reality-virtuality continuum. Telemanipulator Telepresence Tech 1995;2351:282-293. doi: 10.1117/12.197321.

6. Al-khalifah A, McCrindle RJ. Student perceptions of virtual reality as an education medium. In: In proceedings of World Conference on Educational Multimedia, Hypermedia and Telecommunications 2006 (EDMEDIA 2006). Orlando: Association for the Advancement of Computing in Educa- tion (AACE); 2006. p. 2749-2756.

7. Suh HJ. Relationships among presence, learning flow, attitude toward usability, and learning achievement in an augmented reality interactive learning environment. J Educ Inf Media 2008;14:137-165.

8. Davenport JC, Basker RM, Heath JR, Ralph JP, Glantz PO, Hammond P. Tooth preparation. Br Dent J 2001;190:288294. doi: 10.1038/sj.bdj.4800954.

9. Brand HS, Baart JA, Maas NE, Bachet I. Effect of a training model in local anesthesia teaching. J Dent Educ 2010;74: 876-879.

10. Buchanan JA. Use of simulation technology in dental education. J Dent Educ 2001;65:1225-1231.

11. Buchanan JA. Experience with virtual reality-based technology in teaching restorative dental procedures. J Dent Educ 2004;68:1258-1265.

12. Kournetas N, Jaeger B, Axmann D, Groten M, Lachmann $\mathrm{S}$, Weber H, Geis-Gerstorfer J. Assessing the reliability of a digital preparation assistant system used in dental education. J Dent Educ 2004;68:1228-1234.

13. Aragon CE, Zibrowski EM. Does exposure to a procedural video enhance preclinical dental student performance in fixed prosthodontics? J Dent Educ 2008;72:67-71.

14. Robinson PB, Lee JW. The use of real time video magnification for the pre-clinical teaching of crown preparations. Br Dent J 2001;190:506-510. doi: 10.1038/sj. bdj. 4801016.

15. Finkbeiner BL. Four-handed dentistry: a handbook of clinical application and ergonomic concepts. Upper Saddle River: Prentice Hall; 2001.

16. Arnetzl G, Dornhofer R. PREPassistant: a system for evaluating tooth preparations. Int J Comput Dent 2004;7: 187-197.

17. Marras I, Nikolaidis N, Mikrogeorgis G, Lyroudia K, Pitas I. A virtual system for cavity preparation in endodontics. J Dent Educ 2008;72:494-502.

18. Pulijala Y, Ma M, Pears M, Peebles D, Ayoub A. An innovative virtual reality training tool for orthognathic surgery. Int J Oral Maxillofac Surg 2018;47:1199-1205. doi: 10.1016/j.ijom.2018.01.005.

19. Polcar J, Horejsi P. Knowledge acquisition and cyber sickness: a comparison of VR devices in virtual tours. MM Science J 2015:613-616. doi: 10.17973/MMSJ.2015_ 06_201516. 